\title{
The Obstacles of Communication Between Teachers and Students in Chinese Universities and Its Countermeasures*
}

\author{
Gaohe Wang \\ School of Marxism \\ Jinan University \\ Guangzhou, China
}

\begin{abstract}
Maintaining full communication between teachers and students is an inherent requirement for strengthening the construction of teachers' morality in colleges and universities. It is directly related to the growth of college students. At present, some college teachers have various problems in communication with college students: the consciousness of communication needs to be enhanced, the enthusiasm of communication needs to be improved, the communication time needs to be increased, the communication channels need to be increased, and the content of communication needs to be expanded. To eliminate these problems, we must focus on strengthening five aspects of work: strengthening teacher moral education, enhancing communication consciousness; improving teacher evaluation mechanism, improving communication enthusiasm; scientifically coordinating various social roles, increasing communication time; rationally using new media, building three-dimensional communication network; continuously improving their overall quality and expanding communication content.
\end{abstract}

Keywords-college teachers and students; communication; obstacles; response

\section{INTRODUCTION}

Communication is one of the most important behaviors of an organization. As an educational organization where teachers and students coexist and live together, communication is of great significance to it. It is directly related to the growth of college students. At present, most college teachers in China maintain communication with college students through certain channels and methods. However, in general, the communication between teachers and students in colleges and universities is not sufficient, and even shows a certain degree of indifference, which has formed an impact and challenge on the realization of higher education goals, and needs improvement. The emergence of communication problems between teachers and students in colleges and universities in China has both social influences and the reasons for colleges

*Fund Project: This paper is the key project of the ideological and political special project of Jinan University. "Xi Jinping's theory of ideological and political work in colleges and universities organically integrated into the career development of university teachers --- taking Jinan University as an example, the phased outcome of Jinan University's teaching reform project "Xi Jinping's new era of socialism with Chinese characteristics is integrated into university teaching research". and universities, as well as the factors of teachers and college students. Teachers have the most important responsibilities. This article is limited to the length of the article, mainly from the perspective of teachers to analyze the barriers of communication between teachers and students in colleges and universities.

\section{Maintaining Full COMMUNiCATION BetweEN} TEACHERS AND STUDENTS IS AN INHERENT REQUIREMENT FOR STRENGTHENING THE CONSTRUCTION OF TEACHERS' MORALITY IN COLLEGES AND UNIVERSITIES

Teacher morality is the ethical norm and code of conduct that teachers must follow in their educational activities. It is a comprehensive reflection of teachers' attitudes, teaching styles and behaviors in a certain period of time. Teacher's morality is the soul of the teacher. It is embodied in the activities and various links of teaching and educating. One important aspect is that teachers and students should maintain full communication. This is not only an inherent requirement for strengthening the construction of teachers' morality in colleges but also an important way.

\section{A. Maintaining Full Communication Between Teachers and} Students Is the Main Embodiment of Strengthening the Construction of Teachers' Morality

The core of the teacher's morality is the teacher's love. Xia Gaizun, a modern Chinese linguist, said that education can't have no feelings, no love, just like a pond without water, it can't be a pond; without emotion, without love, there is no education. Teacher love is reflected in all aspects of educational activities. The most important thing is to love students. Teachers should not only internalize their love of students as an educational concept, but also externalize them into conscious behaviors, and truly understand and care students, promoting the healthy growth of college students. To do this, teachers must stay in close contact and mingle with the students. Understanding students and caring students includes two levels: First, focus on reality, pay close attention to the life and learning status of college students, timely understand the emotional changes and psychological confusion of college students, and make suggestions for solving various practical problems they encounter. The second is to look at the future, 
care about the future of college students, and think about the life of college students. Through the full communication with college students, college teachers should discover the endowments, interests, hobbies and specialties of each college student, explore and exert their potential, provide correct guidance and sufficient conditions for their growth and development, and gradually cultivate them into a person who has both individual characteristics and comprehensive development that meets the requirements of the times.

\section{B. Maintaining Full Communication Between Teachers and Students Is the Basic Way to Give Play to the Exemplary Role of Teacher's Morality}

Teachers are engaged in teaching and educating people. Not only do they have to use their own knowledge to teach people, but they also need to use their own morality to educate people. As an engineer of the human soul, his every move has a model role and deeply affects students. As the former Soviet educator Kalinin said, the teacher's world outlook, conduct and life affect the whole student in one way or another. The demonstration role of the teacher's morality must be "speech" and "behavior education." Chinese educator Ye Shengtao believes that it is good to teach by example, and that cognition and behavior are inseparable. "Behavior education" is to be a teacher, that is, one word and one behavior is enough for the model of the educated, which requires close contact or even zero contact between teachers and students. Moreover, the demonstration role of teachers' morality to college students cannot be accomplished through one or two educations. It is gradually infiltrated into college students through subtle ways. We often describe it as "slow into the night with the wind, and the things are quiet and silent". Ten years of cultivating trees, educating people for a hundred years, the influence of teachers' morality on students is a "slow effort", which determines the communication between teachers and students must be regular, teachers should slowly guide students with sufficient patience and care, persevere, tireless.

\section{THE MAIN OBSTACLES TO THE COMMUNICATION BETWEEN TEACHERS AND STUDENTS IN COLLEGES AND UNIVERSITIES IN CHINA}

The lack of communication between teachers and students is a common problem in colleges and universities in China. The reasons for the communication problems between teachers and students are complicated. From the perspective of teachers, there are mainly five major obstacles.

\section{A. The Consciousness of Communication Needs to Be Enhanced}

Teachers are engineers of human souls. Every college teacher should correctly recognize the lofty and sacred nature of his profession. As the former Soviet educator Suhomlinski said, teachers should be aware and feel that the fate of every child is his responsibility. The ideal, health and happiness of the person being cultivated in the school depend on his spiritual qualities and the perfection of his thoughts. This requires university teachers to consciously communicate with college students, understand and care for college students, and promote the growth of college students. However, at present, some teachers have insufficient understanding of the sacredness and sublimity of the teacher profession. They hold the idea of "hiring" and think that teachers are working like employers in the enterprise, working for the employer, taking the class, and after class as far as "everything is done," there is no form of communication with college students after class. There are also some teachers who are influenced by bad ideas such as money worship, individualism, and enjoyment. They can't resist the temptation of material and money, talk more about money and benefits, talk less or don't talk about ideals and dedication, and in order to get more income, In the society, he has served as a part-time job with a wide range of names. He turned the cart before the horse and regarded his work as a sideline. He regarded teaching college students as a "crossover" and thought that communicating with college students after class is an extra job, and has nothing to do with income and there are no "benefits" for the individual.

\section{B. The Enthusiasm of Communication Needs to Be Improved}

Most college teachers are aware of the necessity and importance of maintaining communication with college students. However, due to the influence of the current evaluation mechanism of college teachers in China, the enthusiasm of many teachers and college students is significantly reduced, even when they see students, they quickly evade. Because the teacher evaluation mechanism is directly related to the personal interests of teachers' income and job title promotion, it has an important influence on teachers' ideological emotions and work attitudes. The scientific evaluation mechanism can fully mobilize the enthusiasm of teachers to teach and educate people; the unscientific evaluation mechanism will dampen the enthusiasm of teachers to teach and educate people. Generally speaking, the current evaluation mechanism for college teachers in China is still not perfect. Although it has made specific requirements for teaching and scientific research, it is suspected of heavy scientific research and light teaching. In addition, the research work is easy to quantify, how many articles are published, and several topics are hosted at a glance; teaching work is not easy to quantify, and it is not easy to measure whether it is good or bad. This tends to lead some college teachers to believe that the university is a "iron-plated battalion of soldiers." Teaching is difficult to measure and difficult to be seen; and the number of papers and topics is "real", which can directly benefit teachers. Therefore, they put their main focus on scientific research and neglected the teaching to varying degrees. This view and practice is wrong, but there are many examples in colleges and universities that "confirm" this view and practice. For example, some teachers with general teaching effects and good scientific research work have higher titles. However, teachers with good teaching results and general scientific research work are struggling on the title review. The most typical example is the teacher of Shanghai Jiao Tong University, who has passed away. He has been diligent in teaching throughout his life, and his teaching level and his teacher's morality have been praised. However, due to the lack of papers, his title remained at the "Lecturer" until his death at the age of 57. Such an evaluation mechanism can easily dampen the enthusiasm of teachers who are diligent in teaching. Over time, these teachers may also change the focus 
of their work, put research in the first place, put teaching in a secondary position, and the enthusiasm communicating with students is naturally reduced.

\section{The Time for Communication Needs to Be Increased}

College teachers play a variety of social roles. They are teachers for college students, children for parents, husbands or wives for partners, and parents for children. With the development of society, college teachers have taken on more and more roles in society, such as various directors and committee members. In the face of increasing social roles, teachers should reasonably arrange the time that each role is "occupied", in which the role of the teacher should be placed at the top of the list. However, some teachers are now unable to reasonably allocate the time of each role due to various factors. There is less and less work on college students, and there is no deepening communication with college students in one month, one quarter, or even one year is more common. If some teachers hold administrative positions in colleges and universities, teaching and administration "double shoulders." The busy administrative work makes these teachers "hard to move", it is difficult to "care" the students, and the frequency of communication with the students is greatly reduced. Some teachers cannot deal well with the relationship between family roles and teacher roles. They are busy with family affairs all day and have insufficient concern for students. There are also some teachers who cannot deal well with the relationship between various social part-time roles and teachers, such as committee members and directors, and even give up normal classes for college students for social affairs, let alone maintain full communication with college students.

\section{The Channels of Communication Need to Be Increased}

A diverse and multi-level communication network should be built between teachers and students to adapt to different personality, different situations, different problems and different needs of college students. At present, there are two main problems in the communication channels between teachers and students: First, there are fewer channels for communication between teachers and students. Some teachers, especially older teachers, are accustomed to adopting traditional communication channels, such as interviews, writing letters, etc., and are not good at using new media channels, such as QQ, Fetion, Cornet, Weibo, and blogs. Second, in terms of form, there are some channels for teachers and college students to communicate, including both traditional channels and new media channels. However, the functions of these channels have not been fully utilized. For example, traditional channels interviews, no place can be found, teachers cannot be found, and interviews are becoming more and more difficult. New media such as QQ and Fetion are basically in a "stealth" state. I am afraid that college students know that they are "online." The functions of these communication channels are seriously blurred, and the communication effect between teachers and students is greatly reduced. [1]

\section{E. The Content of Communication Needs to Be Expanded}

Article 4 of the first chapter of the Higher Education Law of the People's Republic of China clearly stipulates that higher education must implement the state's educational policy, serve the socialist modernization drive, and combine with productive labor to make educators become the builders and successors of the socialist cause with all-round development in moral, intellectual, and physical, etc.. This profoundly shows that college teachers should not only pay attention to teaching, but also continuously improve the professional quality of college students; it is also necessary to pay attention to educating people and continuously improve the moral quality of college students. This determines that in the communication process, teachers and students should not only discuss professional issues, but also talk about world outlook, outlook on life, and values, and urge college students to do both "learning" and being good people. However, there are some college teachers who are disconnected from teaching and educating people, focusing only on the teaching and communication of professional knowledge, ignoring the life-oriented education for college students. Chinese educator Ye Shengtao believes that thousands of teachings, teaching people to seek truth, learning thousands of times, learning to be real people. As a college teacher, it is not enough to teach homework only. What is more important is to care about the overall development of college students. There are also some professional teachers who believe that students should be prepared for both morality and ethics. However, as a professional teacher, they are mainly responsible for the cultivation of "caliber" of college students. The cultivation of "moral" is a matter for teachers engaged in ideological and political education. This kind of understanding is also not advisable, because "all courses in higher education have the function of educating people, and all teachers have the responsibility of educating. The teachers should take a high-responsibility attitude and use their own behavior as an example, resulting a subtle influence on college students with good thought, morality, quality and personality."[2]

\section{EFFECTIVE WAYS TO PROMOTE THE FULL \\ COMMUNICATION BETWEEN TEACHERS AND STUDENTS IN COLLEGES AND UNIVERSITIES}

Insufficient communication between teachers and students in colleges and universities affects the role of teachers in evangelism teaching and reassure, affects the growth of college students, and it urgently needs to find effective ways to cope.

\section{A. Strengthening the Education of Teachers' Morality Teaching and Enhancing the Consciousness of Communication}

Some college teachers and college students are not strong in their communication. The key is that their teachers' moral consciousness is not high, they lack a correct understanding of the profession of teachers, and they lack resistance to bad ideas such as money worship, individualism and enjoyment. Therefore, it is necessary to strengthen the education of teachers' morality, improve the teachers' moral awareness of college teachers, and enhance their consciousness of communication with college students. The teacher's moral education for college teachers is carried out from the 
perspective of other aspects of intervention. The most important thing is that the education departments and institutions should regularly organize effective teacher education activities. At present, although the educational activities of college teachers' morality are available year after year, there are obvious deficiencies: "The teacher's moral education lacks normative, and it is in a state of arbitrariness and dispensability; the content of teacher's moral education is blurred, lacking the era feelings, political color is strong; teacher moral education methods are single, lacking practicality."[3] In order to solve the problem of communication with college students, it is imperative to popularize the "Teacher Law", "Higher Education Law", "Professional Ethics of Colleges and Universities" and other relevant laws and regulations in all college teachers, so that college teachers can truly understand their own duties and obligations .Because many college teachers have not completely studied the above laws and regulations, and have little knowledge of the contents of these laws and regulations. The understanding of the profession of teachers mainly comes from self-perception, and it is inevitable that there are deviations. This is an important factor of the result of consciousness some college teachers and college students communicating not strong. On the other hand, from the perspective of self-discipline, this is also the most important aspect. Teachers should constantly improve their moral cultivation through the method of "being cautious when they are alone", and internalize the principles and norms of teacher morality into beliefs, beliefs, and the quality of personality, not only to teach and educate people as a profession, but also a career, a kind of fun, to regard the world of talent and education as a great fortune in life, to face the temptation of fame and fortune, to be willing, dedication, As Lu Xun said, as long as you can cultivate a flower, you can do it as a decaying rot. It is not only to teach and educate people as a profession, but also to be a career, a kind of fun, to regard the talents of the world as a great fortune in life, to face the temptation of fame and fortune Indifferently, to be willing to contribute, to achieve as Lu Xun said, as long as you can cultivate a flower, you can do it as a decaying rot.

\section{B. Improving the Teacher Evaluation Mechanism and Increasing the Enthusiasm of Communication}

To improve the enthusiasm of college teachers and college students, we must constantly improve the current college teacher evaluation mechanism. The teacher's first duty is to teach and educate people. Therefore, in the evaluation of teachers, the teaching work should be put in the first place. Of course, scientific research is also very important. To do a good job of teaching, it is inseparable from scientific research the two are mutually influential and mutually reinforcing. However, there are two obvious shortcomings in the evaluation mechanism of college teachers in China: one is that teaching and research are more focused on scientific research, and the other is that the quality and quantity of scientific research results are more important than quantity. This can easily lead some teachers to pay attention to the number of scientific research, neglect teaching, and neglect communication with college students. How to improve the current college teacher evaluation mechanism is something that the relevant education departments should consider. Some universities have already carried out useful explorations. For example, since 2012, Fudan University has implemented a new senior job evaluation method in all departments of the school, that is, the representative system. Its main content is to dilute the "hard bars and hard bars" of past job evaluation. Teachers only need to complete high-quality research results and pass expert review, even if there is only one article, even if it is not published in "authoritative" or "core" journals, you can also get a chance to participate in a higher level of professional review. Through the pilots of the previous two years, Fudan University has more than 10 teachers who have been promoted through this new system. The practice of Sun Yat-sen University's College of Education is also worth learning. It is a lecturer who has a good teaching effect and is widely praised for his teacher's morality, but whose scientific research results are not up to the title of associate professor. He has established a new title called Senior Lecturer at the associate professor level, it has found a new "outlet" for some teachers who are diligent in teaching and "bitter" in scientific research. These beneficial explorations of Fudan University and Sun Yat-sen University are conducive to stimulating teachers to find a balance between teaching, research and management, and to mobilize the enthusiasm of teachers communicating with college students. However, these explorations are just beginning, and more education departments and institutions need to explore their own reality. The primary criterion for exploration is not whether the research work is done well, but whether the teaching work is done well.

\section{Scientifically Coordinating Various Social Roles and Increasing Communication Time}

With the rapid development of the economy and society, there are more and more social roles undertaken by college teachers. This is an inevitable trend and nothing wrong. However, in the face of multiple social roles, college teachers should scientifically coordinate the relationship between various roles and reasonably "allocate" the time of each role. Among them, the role of teachers should be the first, and teachers should set aside time to communicate with college students. As for how long it takes, it is not possible to make a one-size-fits-all approach, depending on the specific circumstances of each teacher. In general, the time for college teachers to communicate with college students can be divided into fixed time and random time. Fixed time means that the teacher should set up a relatively stable period of time to communicate with the college students, such as 9-10-10 every night. In the absence of special circumstances, teachers should discuss their concerns with students in a variety of ways, such as QQ, Fetion, and e-mail, on a regular basis every day. Setting a fixed period of time to communicate with college students is conducive to motivating college students to form a habit of communicating with teachers, having problems finding teachers, and enhancing college students' trust in teachers. Random time mainly means that teachers should keep communication channels open 24 hours a day. When college students encounter urgent problems, they can contact the teachers in time to seek help and doubt or other help. 


\section{Rational Use of New Media to Build a Three-dimensional Communication Network}

The three-dimensional communication network between teachers and students is composed of diverse and multi-level communication channels. Diversification means that teacherstudent communication must not only maintain traditional communication methods, but also open up new channels according to the development of society to adapt to the new situation, new situation and new requirements of college students. [4] Multi-level means that the communication channels between teachers and students cannot be uniform. It is necessary to consider the different characteristics of college students, different issues, different needs and other practical situations, so that every college student can find channels to communicate with teachers. The construction of the threedimensional communication channel between teachers and students must first be based on the principle of facilitating students, rather than the principle of facilitating teachers. What kind of communication methods are most preferred and most commonly used by college students, and teachers should try to open up any communication channels. In recent years, with the development of the network, college students are increasingly relying on new media for communication, such as short number, QQ, Weibo, space, blog, e-mail and so on. Teachers should use these new media reasonably to communicate fully with college students. At present, most college students have opened mobile phone short numbers. The mobile phone short number is divided into "groups". A group of colleges and universities, after paying a certain fee, users in the group can talk to each other for an unlimited time. In accordance with this situation, teachers of all colleges and universities should open mobile phone short numbers and join the "group" of college students. This not only saves money for college students, but also reflects the willingness of teachers to communicate with college students, thus increasing the intimacy of college students. It should be emphasized that the establishment of these new media communication channels is only the beginning. More importantly, teachers should promptly reply to the messages made by college students through these channels. QQ and Fetion should always stay "online", but not for college students to wait. Only then will more and more students choose these channels to communicate with teachers.

\section{E. Continuously Improving Their Overall Quality and Expanding Communication Content}

The talents cultivated in colleges and universities are the people of all-round development of morality and intelligence. This determines the range of topics involved in the communication between teachers and students in colleges and universities. It has a wide range of topics, including professional issues, ideological issues, and life issues. It can be said that all the problems encountered during the growth of college students are related to teachers. In order to help college students correctly analyze and solve various problems encountered, teachers must constantly improve their overall quality. First, we must constantly enrich our knowledge system, both "special" and " learned". In today's Internet age, the methods and ways for college students to acquire knowledge and information are increasingly diverse. It is often the case that college students have more information in some aspects than teachers. This requires teachers to read a lot of books, constantly enriching and timely updating the original knowledge structure to ensure accurate answer to college students' knowledge confusion. Second, we must constantly improve our ideological and political quality and moral cultivation, and make ourselves a person with noble sentiments. This aspect is because the right person must first be the right person. Only with noble sentiment can we influence and educate the university students in the teaching and life with their own "German". On the other hand, because the university students are encountering various questions of world outlook, outlook on life, and values, they will often choose a teacher who they trust more and hope that teachers can help them solve their problems. If teachers are unable to do anything about these ideological issues raised by college students, college students will feel helpless and disappointed. Therefore, college teachers must constantly improve their overall quality, so that they are not only the faculty members of their own disciplines, but also the mentor and moral guide of college students.

\section{CONCLUSION}

In short, only teachers and students can always maintain the mutual communication of information, thoughts and emotions, and teachers can fully play the role of evangelism and teaching, and students can realize the all-round development of morality, intelligence and body. The problem of communication between teachers and students is a complex social problem. It has both social influences and educational institutions. It also has the factors of college teachers and college students themselves. Similarly, the solution to the problem of communication between teachers and students requires social, educational institutions, teachers, college students and other parties to work together and take a multipronged approach. From the teacher's point of view, teachers should consciously communicate with college students and construct a communication channel combining traditional methods with modern network technology methods, so that they not only become the disseminators of knowledge, but also the guides of morality.

\section{REFERENCES}

[1] Ding Ke. "Thinking about the Intersubjectivity of Network Ideological and Political Education", Theory and Reform, No. 6, 2011.

[2] Opinions of the Central Committee of the Communist Party of China and the State Council on Further Strengthening and Improving College Students' Ideological and Political Education [N]. China Education News, 2004-10-15 (1).

[3] He Xianglin, Huang Wujing, Xu Li. "Teacher-oriented, teacher's morality is the soul-Research report on the current situation of teacher's moral construction in China" (below), School Party Building and Ideological Education, 2010, Issue 10 .

[4] Li Ling. "Challenges, Opportunities and Countermeasures of Traditional Media in the Weibo Era", Theoretical Exploration, No. 3, 2011. 